\title{
Sex Differences in the Nonlinear Association Between BMI and LDL Cholesterol in Middle-Aged and Older Adults: Results from two Nationally Representative Surveys of China
}

\author{
Haibin Li ( $\sim 15910681644 @ 126 . c o m)$ \\ Jiahui Ma \\ Peking University First Hospital \\ Deqiang Zheng \\ Capital Medical University \\ Xia Li \\ La Trobe University - Beechworth Campus: La Trobe University \\ Xiuhua Guo \\ Capital Medical University \\ Jing Wang \\ Beijing Chaoyang Hospital
}

Capital Medical University Affiliated Beijing Chaoyang Hospital https://orcid.org/0000-0002-6932-982X

Pixiong Su

Beijing Chao-Yang Hospital: Beijing Chaoyang Hospital

\section{Research Article}

Keywords: BMI, LDL-C, nonlinear relationship, sex differences, generalized additive models

Posted Date: August 10th, 2021

DOI: https://doi.org/10.21203/rs.3.rs-779196/v1

License: (c) (i) This work is licensed under a Creative Commons Attribution 4.0 International License. Read Full License 


\section{Abstract}

Background: The association between body mass index (BMI) and low-density lipoprotein cholesterol (LDL-C) in middleaged and older man and women was understudied. We aimed to explore whether there were sex differences in this relationship in a large sample of Chinese adults.

Methods: Participants in the China Health and Retirement Longitudinal Study (CHARLS, 2011-2012) ( $\mathrm{n}=7485)$ and the China Health and Nutrition Survey (CHNS, 2009) (n=4788) were cross-sectionally investigated. Generalized additive models with a smooth function for BMI and a smooth-factor interaction for BMI with sex were performed and stratified by age and metabolic syndrome. Segment linear splines regressions were fitted to calculate the slopes with the different breakpoints.

Results: Among the 12273 participants aged 45 to 75 years, 5780 (47.1\%) were males. The nonlinear relationship between BMI and LDL-C was observed in females and males $\left(P_{\text {interaction }}<0.001\right)$. The slopes of the BMI and LDL-C association changed $(P<0.001)$ at BMI $22.5 \mathrm{~kg} / \mathrm{m}^{2}$ in females and $27.5 \mathrm{~kg} / \mathrm{m}^{2}$ in males. Below these BMI breakpoints,

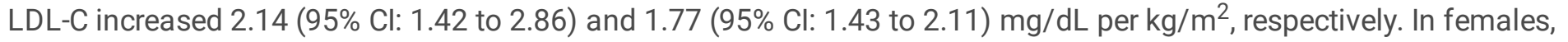
there was a plateau at BMI values of $22.5-27.5 \mathrm{~kg} / \mathrm{m}^{2}$, and then gradually increased after a BMl of $27.5 \mathrm{~kg} / \mathrm{m}^{2}$. However, LDL-C declined -1.84 (95\% Cl: -3.01 to -0.66$) \mathrm{mg} / \mathrm{dL}$ per $\mathrm{kg} / \mathrm{m}^{2}$ above BMI of $27.5 \mathrm{~kg} / \mathrm{m}^{2}$ in males. The pattern of sex and BMI-LDL-C association was similar in all age groups but modified by the number of metabolic syndrome criteria.

Conclusions: The BMI and LDL-C relationship was inverted U-shaped in males and approximately linear in females.

\section{Introduction}

Higher body mass index (BMI), as an indicator of overweight and obesity, troubled more and more people worldwide and caused serious public health concern. It has been shown that, by 2030 , the prevalence of overweight and obese will be increase to $23 \%$ and $32 \%$ respectively [1]. Overweight and obesity has affected all ages especially for the elderly adults, and closely associated with the occurrence of metabolic disorders and cardiovascular disease (CVD) [2, 3]. One study found that for every $5 \mathrm{~kg} / \mathrm{m}^{2}$ increased in BMI, the average of all-cause mortality and vascular mortality would increase by $30 \%$ and $40 \%$ separately [4].

Metabolic syndrome (MS) as one of the causes of CVD that associated with higher BMI and dyslipidemia which contributed by elevated triglycerides and reduced how-density lipoprotein cholesterol (HDL-C), but without a clear alter of low-density lipoprotein cholesterol (LDL-C) [5]. However, a large body of epidemiology and Mendelian randomization studies have suggested that LDL-C is a well-established risk factor for CVD [6]. Moreover, compared with HDL-C and triglyceride, the concentration of LDL-C and its therapeutic modification are greater associated with CVD [7-9].

Previous studies are mainly explored the linear relationship between LDL-C and BMI in the small or selected samples, remaining limited data on potential sex differences. For example, a study performed in the US population suggested that LDL-C was linearly related to BMI [10]. Another study conducted with US children group also indicated that BMI was strong determinants of lipid and lipoprotein levels [11]. While one study showed that LDL-C only increased with greater $\mathrm{BMI}$ among younger subjects, but not among men over 50 years [12]. Most notably, a recent study investigated both US and Spain large population found that there is not always a linear relationship between LDL-C and BMI, i.e., age and metabolic status play essential roles and effects on relationship. However, although visceral fat area was found positively correlated with serum LDL-C levels in a nondiabetic Chinese population [13], the association between BMI and LDL-C are yet to be clearly defined, and further research about the sex difference in above association is still needed since the distribution of fat differed between sex.

Loading [MathJax]/jax/output/CommonHTML/fonts/TeX/fontdata.js

Page 2/12 
This study is aimed to explore the sex differences in the nonlinear relationship between BMI and LDL-C in the Chinese adult population and stratified by age groups and MS status. The findings could help to provide a detailed dose-response relationship between LDL-C and BMI, shedding lights on the prevention and treatment of CVD.

\section{Methods}

\section{Study Population}

We analyzed two cross-sectional nationally representative datasets in China from the China Health and Nutrition Survey (CHNS) and the China Health and Retirement Longitudinal Study (CHARLS). Detailed descriptions of these two studies have been published $[14,15]$. Briefly, the CHNS is an ongoing open cohort designed to monitor and understand the association between socio-economic factors and health change in China [14]. The CHNS was initially conducted in 1989, while the biomarker data was first collected in 2009. The CHARLS is a nationally representative longitudinal study conducted in 2011-12 from 150 counties of 28 provinces in China, with information on demographic characteristics, medical history, lifestyles, and laboratory testing on a set of individuals [15]. Written informed consents were obtained from all participants from CHNS and CHARLS.

In the current study, we identified all adults aged 45 to 75 years with the availability data of blood biomarkers and anthropometric measures in both these two datasets. Furthermore, participants with missing baseline covariates or having cardiovascular disease or cancer were excluded. Finally, a total of 12273 participants $(n=4788$ for CHNS; $n=$ 7485 for CHARLS) were included in the final analysis (Fig. 1).

\section{Measures}

Information on age, sex, residence (urban or rural), education level (< high school or $\geq$ high school), marital status (married or others), current smoking and drinking status (yes or no), and medical history and drugs use were obtained from the standard questionnaires and harmonized for both two datasets. Blood samples were obtained and measured for serum lipids (total cholesterol, triglycerides, LDL-C, HDL-C) and blood glucose. Data on anthropometry (BMI and waist circumference (WC) and blood pressure were measured with standard methods. The cardiometabolic health was defined as the number of MS criteria (excluding the WC criterion) enlisted in the harmonized joint MS definition [16].

\section{Statistical analysis}

Participant characteristics by sex were described in the pooled database and separately in CHARLS and CHNS. Differences between sexes in continuous variables were assessed using the Student's t-test or Mann-Whitney U test and in categorical variables using Pearson's $\chi^{2}$ test.

To explore the nonlinear relationship between BMI and LDL-C in women and men, generalized additive models (GAMs) with a factor-smooth interaction between sex (factor) and BMI (smooth function) were fitted. Models were adjusted for age, residence, education levels, marital status, drinking, smoking status, and cohort sources. Thus, model can be expressed as follows:

$Y_{i}=\beta_{0}+\left[f_{B M I} \operatorname{SEX}\left(B M I_{i}\right) \times \mathrm{I}\left(\mathrm{x}_{\mathrm{sex}}=1\right)\right]+\left[f_{B M I} \stackrel{-}{\operatorname{sex}}\left(B M I_{i}\right) \times \mathrm{I}\left(\mathrm{x}_{\mathrm{sex}}=0\right)\right]+\beta_{\mathrm{sex}} x_{\mathrm{sex}}+\beta \operatorname{Cov}_{i}^{T}+\epsilon_{i}$

where $Y_{i}$ is the response of LDL-C for individual $i, f_{B M I}$ is the nonparametric smooth function of BMI, $\beta_{\mathrm{sex}} X_{\mathrm{sex}}$ is the main effect of the predictor variable sex, $\beta \operatorname{Cov}_{i}^{T}$ is the linear predictor of covariables, and $\epsilon_{i}$ is the error terms, which are assumed to he normallv distributed Then we nerformed the multivariable adjusted generalized linear model using linear Loading [MathJax]/jax/output/CommonHTML/fonts/TeX/fontdata.js 
splines, with the break points identified from GAMs smooth plot. In addition, to describe how the relationship between $\mathrm{BMI}$ and LDL-C varied according to age and cardiometabolic health, we also performed GAMs stratified by the agegroups (45-54, 55-64, 65-75 years) and the number of MS criteria (excluding the WC criterion).

All analyses were performed using Stata 16.0 (Stata Corp LLC, College Station, Texas, US) and the gam function of "mgcv" package in the R statistical software (version 4.0.2). Two-tailed $P$ values $<0.05$ were considered statistically significant.

\section{Results}

\section{Baseline characteristics}

A total of 12273 adults (6493 females and 5780 males) aged 45-75 years were included in this analysis. Table 1 shows the characteristics of study population by sexes. There were significant differences in female and male in age, education level, marital status, smoking, drinking, diastolic blood pressure, BMI, WC, glucose, triglycerides, HDL-C, and count of MS criteria $(P<0.005)$. Baseline characteristics stratified by CHARLS and CHNS are showed in the Supplementary File Table S1.

\section{Relationship of BMI and LDL-C}

Table 2 shows the estimated regression coefficients from the GAMs with the factor-smooth interaction terms for sex*BMI. The interaction sex*BMI, older age, residence, and education were statistically significantly associated with LDL-C. The estimated smooth functions in Fig. 2 shows the nonlinear relationship between BMI and LDL-C in female and male ( $P<0.001$ for smooth terms). Table 3 shows the results from generalized linear models using linear splines. In female, BMI was linearly associated with LDL-C below a BMI of $22.5 \mathrm{~kg} / \mathrm{m}^{2}$ (slope: $2.14,95 \% \mathrm{Cl}: 1.42$ to 2.86); and followed a plateau at BMI values of $22.5-27.5 \mathrm{~kg} / \mathrm{m}^{2}$ (slope: $0.38,95 \% \mathrm{Cl}:-0.22$ to 0.98 ); then gradually increased after BMI of $27.5 \mathrm{~kg} / \mathrm{m}^{2}$ (slope: $0.68,95 \% \mathrm{Cl}:-0.31$ to 1.67 ). In male, the association between BMI and LDL-C is inverse Ushaped, with the break point at BMI of $27.5 \mathrm{~kg} / \mathrm{m}^{2}$ (slope: $1.77,95 \% \mathrm{Cl}: 1.43$ to 2.11 for $\mathrm{BMI}<27.5 \mathrm{~kg} / \mathrm{m}^{2}$; slope: -1.84 , 95\% Cl: -3.01 to -0.66 for $\mathrm{BMI} \geq 27.5 \mathrm{~kg} / \mathrm{m}^{2}$ ).

\section{Subgroup Analysis}

The nonlinear relationship between BMI and LDL-C in female and male were obvious in all age-groups and only with 1 of MS criteria (Figure S1 and Figure S2 in the Supplementary File).

\section{Discussion}

In this study, we measured the dose-response relationship of BMI and LDL-C in Asian population, and further explored the association between BMI and LDL-C in sex subgroup and different MS status. It has been found that, in the population with normal or light weight $\left(\mathrm{BMI}<22.5 \mathrm{~kg} / \mathrm{m}^{2}\right)$, the association between BMI and LDL-C was linearly and positively correlated, in the overweight population, with the increase of BMI, the level of LDL-C gradually tended to be flat or even decreased. The trend of the above association was also different between genders, and the inverted-U shape was showed in male.

The association between BMI and lipid metabolites was assessed chiefly in HDL-C or triglyceride levels with the result of linear association, but the dose-response relationship of BMI and LDL-C has occasionally been carried out and the result remains inconsistent. Several studies have indicated a positive association between BMI and LDL-C [17-20], whereas 
representative data from the U.S. and Spain found an inverted U-shaped association between BMI or WC and LDL-C [6], which is consist with a similar study with the nondiabetic American Indians [22]. In addition, some studies suggested that association between BMI and LDL-C differ between sex and age subgroup [20,23]. Although the above studies have initially pointed out the association between BMI and LDL-C, it is limited to the European and American population, and most of the studies only explored the single sex. This study based on the Chinses population, estimating the ascending and descending slopes, as well as inflection points, comprehensively discussing the association between BMI and LDL-C in sex, age, and MS statues subgroups.

The results of the present study suggested that, based on the Chinese population, the association between BMI and LDL$\mathrm{C}$ showed as an inverted U-shape, which is consist with previous two studies conducted with the U.S. and Spain populations [6, 22]. While WC and LDL-C showed as an inclined S-shape. The above epidemiological findings have also been supported by the studies of biological mechanisms. In particular, in non-obese people $\left(\mathrm{BMI}<25 \mathrm{~kg} / \mathrm{m}^{2}\right)$, triglycerides are converted into cholesterol rich intermediate density lipoprotein (IDL) and LDL for adipogenesis, leading a positive correlation between BMI and LDL in the lean individuals [6]. However, triglycerides may be stored in very low density lipoprotein (VLDL) when lipid deposition in adipose tissue reaches the maximum limit or other exists lipid metabolism disorders, resulting in a decrease in the formation of LDL [24]. Another possible explanation is that adipose tissue store large amounts of cholesterol, thus buffering the cholesterol load of the liver [25]. A study has pointed out that the secretion of bile cholesterol in obese people increases gradually with the accumulation of adipose cell [26]. Therefore, in obese people, normal LDL-C levels may suggest that increased adipocytes are maintaining cholesterol homeostasis. In addition, our study first found that the association between WC and LDL-C showed as an inclined Sshape, which is inconsistent with the association between BMI and LDL-C and the results of previous study. It is well known that the obesity types and fat distribution of Asians and Westerners are different. In addition, with the increase of weight, adipose cell is more likely to accumulate in the abdomen for men, while it is more likely to accumulate in the lower body for woman [27]. Therefore, the gender ratio of the included population will lead to differences in results. Taken together, both ethnic differences and the sex ratio of the recruited subjects may cause the inconsistence, however, more direct evidence of the underlying mechanism regarding the association will be needed.

The performance of the association between BMI and LDL-C in sex subgroup has also been investigated. The inverted Ushape is obviously showed in the male group while it disappeared in the female group. The majority of studies on the above-mentioned associations are carried out in a single sex, especially in men. Moreover, previous study suggested that, after avoiding the confounding factor of body fat percentage, the association of physical fitness level and that plasma lipid profiles between male and female is different [28]. In addition, subjects included in our study are over 45 years old, and a study indicated that the level of LDL-C has been affected by menopausal status, i.e., post-menopause female have higher concentrations of LDL-C [29-31]. Thus, we assume that differences in hormonal status between male and female may lead to different associations between BMI and LDL-C. Some studies have shown that BMI and LDL-C have a positive linear relationship in female. Quantitative studies have also shown that LDL-C of female with BMI between 27.1 $\mathrm{kg} / \mathrm{m}^{2}$ and $30.0 \mathrm{~kg} / \mathrm{m}^{2}$ increased by $17 \mathrm{mg} / \mathrm{dl}$ compared with subjects whose BMI between $21.1 \mathrm{~kg} / \mathrm{m}^{2}$ and $23.0 \mathrm{~kg} / \mathrm{m}^{2}$ [23]. This study also found that LDL-C increased with $\mathrm{BMI}$, moreover, it is first time showed that there were two turning points in the association between BMI and LDL-C, that is, the slope began to flatten near the edge of obesity, and gradually increased again when BMI reached $27.0 \mathrm{~kg} / \mathrm{m}^{2}$. Although we speculate that hormonal status may be responsible for above association, the specific mechanism remains to be further investigated.

Our results supported that the MS status played a role in the association between BMI and LDL-C, i.e., with aggravation of metabolic impairment (number of MS criteria), the turning point of the association curve between BMI and LDL-C gradually appeared earlier. In the extreme group that the subjects had three or four MS criterias, the association trend in male was weakened, while it was more unstable in female. Similar results have been reported in the US population Loading [MathJax]/jax/output/CommonHTML/fonts/TeX/fontdata.js : subgroups separately and provided a thorough and detailed 
dose-response relationship between BMI and LDL-C. It is well known that $\mathrm{MS}$ is related to the increase of BMI. A study even pointed out that MS is caused by the abnormal function of adipose tissue, that is, adipose tissue reached the limit of functional capacity. Another reason may be that, in the regulation of homeostasis mechanism, lipid transport cholesterol may reduce the risk of diabetes and produce high levels of LDL-C. However, after the homeostasis mechanism broken, abnormal cholesterol synthesis and transport will also break the linear relationship between BMI and LDL-C.

Two limitations of this study are addressed. First, this study is a cross-sectional study, which is not able to explain the causal relationship between BMI and LDL-C. Second, in this study, the number of MS criteria was used to represent the severity of MS, where need more accurate quantitative indicators to explore the association between BMI and LDL-C.

\section{Conclusions}

Our study suggested LDL-C increased with BMI in both female and male lean individuals. Trends of the dose-response curve of BMI and LDL-C changed slightly in the different sexes, ages, and MS status. Overall, reducing BMI may lower the level of LDL-C to some extent, which is beneficial to the prevention of CVD.

\section{Declarations}

\section{Conflicts of Interest: None.}

Acknowledgement: We thank the CHNS and CHARLS research team and field team for collecting the data and making the data publicly accessible.

This analysis uses data or information from the Harmonized CHARLS data set and Codebook, Version C as of April 2018 developed by the Gateway to Global Aging Data. The development of the Harmonized CHARLS was funded by the National Institute on Ageing (R01 AG030153, RC2 AG036619, and R03 AG043052). For more information, please refer to www.g2aging.org.

This research uses data from China Health and Nutrition Survey (CHNS). We thank the National Institute for Nutrition and Health, China Center for Disease Control and Prevention, Carolina Population Center (P2C HD050924,T32 HD007168), the University of North Carolina at Chapel Hill, the NIH (R01-HD30880, DK056350, R24 HD050924 and R01HD38700) and the NIH Fogarty International Center (D43 TW009077, D43 TW007709) for financial support for the CHNS data collection and analysis files from 1989 to 2015 and future surveys, and the China-Japan Friendship Hospital, Ministry of Health for support for CHNS 2009, Chinese National Human Genome Center at Shanghai since 2009 and Beijing Municipal Center for Disease Prevention and Control since 2011.

\section{References}

1. Kelly T, Yang W, Chen CS, Reynolds K, He J. Global burden of obesity in 2005 and projections to 2030. Int J Obes (Lond). 2008;32:1431-7.

2. Silva IT, Sanches LB, Mello AP, Damasceno NR. [Impact of C-reactive protein on cardiovascular risk in adolescents]. Arq Bras Cardiol. 2010;94:585-91.

3. Kalish VB. Obesity in Older Adults. Prim Care. 2016;43:137-44. ix.

4. Whitlock G, Lewington S, Sherliker P, Clarke R, Emberson J, Halsey J, Qizilbash N, Collins R, Peto R. Body-mass index and cause-specific mortality in 900000 adults: collaborative analyses of 57 prospective studies. Lancet.

2009;373:1083-96

Loading [MathJax]/jax/output/CommonHTML/fonts/TeX/fontdata.js

Page 6/12 
5. Grundy SM. Atherogenic dyslipidemia associated with metabolic syndrome and insulin resistance. Clin Cornerstone. 2006;8(Suppl 1):21-7.

6. Laclaustra M, Lopez-Garcia E, Civeira F, Garcia-Esquinas E, Graciani A, Guallar-Castillon P, Banegas JR, RodriguezArtalejo F. LDL Cholesterol Rises With BMI Only in Lean Individuals: Cross-sectional U.S. and Spanish Representative Data. Diabetes Care. 2018;41:2195-201.

7. Ference BA, Majeed F, Penumetcha R, Flack JM, Brook RD. Effect of naturally random allocation to lower low-density lipoprotein cholesterol on the risk of coronary heart disease mediated by polymorphisms in NPC1L1, HMGCR, or both: a 2 × 2 factorial Mendelian randomization study. J Am Coll Cardiol. 2015;65:1552-61.

8. Sarwar N, Sandhu MS, Ricketts SL, Butterworth AS, Di Angelantonio E, Boekholdt SM, Ouwehand W, Watkins H, Samani NJ, Saleheen D, et al. Triglyceride-mediated pathways and coronary disease: collaborative analysis of 101 studies. Lancet. 2010;375:1634-9.

9. Holmes MV, Asselbergs FW, Palmer TM, Drenos F, Lanktree MB, Nelson CP, Dale CE, Padmanabhan S, Finan C, Swerdlow DI, et al. Mendelian randomization of blood lipids for coronary heart disease. Eur Heart J. 2015;36:53950.

10. McLaughlin T, Allison G, Abbasi F, Lamendola C, Reaven G. Prevalence of insulin resistance and associated cardiovascular disease risk factors among normal weight, overweight, and obese individuals. Metabolism. 2004;53:495-9.

11. DeStefano F, Berg RL, Griese GG Jr. Determinants of serum lipid and lipoprotein concentrations in children. Epidemiology. 1995;6:446-9.

12. Maki KC, Kritsch K, Foley S, Soneru I, Davidson MH. Age-dependence of the relationship between adiposity and serum low density lipoprotein cholesterol in men. J Am Coll Nutr. 1997;16:578-83.

13. Luo Y, Ma X, Shen Y, Hao Y, Hu Y, Xiao Y, Bao Y, Jia W. Positive relationship between serum low-density lipoprotein cholesterol levels and visceral fat in a Chinese nondiabetic population. PLoS One. 2014;9:e112715.

14. Popkin BM, Du S, Zhai F, Zhang B. Cohort Profile: The China Health and Nutrition Survey-monitoring and understanding socio-economic and health change in China, 1989-2011. Int J Epidemiol. 2010;39:1435-40.

15. Zhao Y, Hu Y, Smith JP, Strauss J, Yang G. Cohort profile: the China Health and Retirement Longitudinal Study (CHARLS). Int J Epidemiol. 2014;43:61-8.

16. Alberti KG, Eckel RH, Grundy SM, Zimmet PZ, Cleeman JI, Donato KA, Fruchart JC, James WP, Loria CM, Smith SC Jr, et al. Harmonizing the metabolic syndrome: a joint interim statement of the International Diabetes Federation Task Force on Epidemiology and Prevention; National Heart, Lung, and Blood Institute; American Heart Association; World Heart Federation; International Atherosclerosis Society; and International Association for the Study of Obesity. Circulation. 2009;120:1640-5.

17. Terry RB, Wood PD, Haskell WL, Stefanick ML, Krauss RM. Regional adiposity patterns in relation to lipids, lipoprotein cholesterol, and lipoprotein subfraction mass in men. J Clin Endocrinol Metab. 1989;68:191-9.

18. Seidell JC, Cigolini M, Deslypere JP, Charzewska J, Ellsinger BM, Cruz A. Body fat distribution in relation to serum lipids and blood pressure in 38-year-old European men: the European fat distribution study. Atherosclerosis. 1991;86:251-60.

19. Beckles GL, Miller GJ, Alexis SD, Price SG, Kirkwood BR, Carson DC, Byam NT. Obesity in women in an urban Trinidadian community. Prevalence and associated characteristics. Int J Obes. 1985;9:127-35.

20. Denke MA, Sempos CT, Grundy SM. Excess body weight. An underrecognized contributor to high blood cholesterol levels in white American men. Arch Intern Med. 1993;153:1093-103.

21. Zamboni M, Armellini F, Cominacini L, Turcato E, Todesco T, Bissoli L, Micciolo R, Bergamo-Andreis IA, Bosello 0. nhanitu, and manianal hod, fant dintrihution in man. anparate and joint relationships to glucose tolerance and plasma Loading [MathJax]/jax/output/CommonHTML/fonts/TeX/fontdata.js 
lipoproteins. Am J Clin Nutr. 1994;60:682-7.

22. Hu D, Hannah J, Gray RS, Jablonski KA, Henderson JA, Robbins DC, Lee ET, Welty TK, Howard BV. Effects of obesity and body fat distribution on lipids and lipoproteins in nondiabetic American Indians: The Strong Heart Study. Obes Res. 2000;8:411-21.

23. Denke MA, Sempos CT, Grundy SM. Excess body weight. An under-recognized contributor to dyslipidemia in white American women. Arch Intern Med. 1994;154:401-10.

24. Laclaustra M, Corella D, Ordovas JM. Metabolic syndrome pathophysiology: the role of adipose tissue. Nutr Metab Cardiovasc Dis. 2007;17:125-39.

25. Le Lay S, Ferré P, Dugail I. Adipocyte cholesterol balance in obesity. Biochem Soc Trans. 2004;32:103-6.

26. Grundy SM, Barnett JP. Metabolic and health complications of obesity. Dis Mon. 1990;36:641-731.

27. Tanaka H, Kakiyama T, Takahara K, Yamauchi M, Tanaka M, Sasaki J, Taniguchi T, Matsuo H, Shindo M. The association among fat distribution, physical fitness, and the risk factors of cardiovascular disease in obese women. Obes Res. 1995;3(Suppl 5):649s-653s.

28. Tanaka HYM, Tanaka M, Sasaki J, Shindo M. Abnormally lower HDL-cholesterol levels in relation to physical fitness. Circulation. 1989;80:511.

29. Perry AC, Applegate EB, Allison ML, Miller PC, Signorile JF. Relation between anthropometric measures of fat distribution and cardiovascular risk factors in overweight pre- and postmenopausal women. Am J Clin Nutr. 1997;66:829-36.

30. Gordon T, Kannel WB, Hjortland MC, McNamara PM. Menopause and coronary heart disease. The Framingham Study. Ann Intern Med. 1978;89:157-61.

31. Matthews KA, Meilahn E, Kuller LH, Kelsey SF, Caggiula AW, Wing RR. Menopause and risk factors for coronary heart disease. N Engl J Med. 1989;321:641-6.

\section{Tables}


Table 1

Baseline Characteristics by Sex in CHARLS and CHNS

\begin{tabular}{|c|c|c|c|}
\hline & Female $(n=6493)$ & Male $(n=5780)$ & $P$ value \\
\hline Age, years, mean (SD) & $57.16(8.06)$ & $57.91(8.07)$ & $<0.001$ \\
\hline $45-54$ & $2642(40.69)$ & $2148(37.16)$ & \\
\hline $55-64$ & $2536(39.06)$ & $2331(40.33)$ & \\
\hline $65-75$ & $1315(20.25)$ & $1301(22.51)$ & \\
\hline Rural residence, $n(\%)$ & $4302(66.26)$ & $3896(67.40)$ & 0.18 \\
\hline High school or above, n (\%) & $694(10.69)$ & $1054(18.24)$ & $<0.001$ \\
\hline Married, n (\%) & $5411(83.34)$ & $5218(90.28)$ & $<0.001$ \\
\hline Drinking, n (\%) & $741(11.41)$ & $3461(59.88)$ & $<0.001$ \\
\hline Smoking, n (\%) & $340(5.24)$ & $3449(59.67)$ & $<0.001$ \\
\hline Body mass index, $\mathrm{kg} / \mathrm{m}^{2}$, mean (SD) & $23.89(3.53)$ & $23.13(3.31)$ & $<0.001$ \\
\hline Waist circumference, $\mathrm{cm}$, mean (SD) & $83.88(11.47)$ & $84.30(11.15)$ & 0.040 \\
\hline Systolic BP, mmHg, mean (SD) & $129.02(20.97)$ & $129.42(19.22)$ & 0.26 \\
\hline Diastolic BP, mmHg, mean (SD) & $77.73(12.02)$ & 79.09 (12.49) & $<0.001$ \\
\hline Glucose (mg/dl), mean (SD) & $121.82(34.99)$ & $113.65(34.19)$ & $<0.001$ \\
\hline LDL cholesterol (mg/dl), mean (SD) & $105.25(33.34)$ & $106.43(34.17)$ & 0.052 \\
\hline Triglycerides (mg/dl), median (IQR) & $114.17(80.54,165.49)$ & $103.54(72.57,160.18)$ & $<0.001$ \\
\hline HDL cholesterol (mg/dl), mean (SD) & $53.97(16.49)$ & $52.62(18.73)$ & $<0.001$ \\
\hline Count of MS criteria, n (\%) & & & $<0.001$ \\
\hline 0 & $965(14.86)$ & $961(16.63)$ & \\
\hline 1 & $1936(29.82)$ & 1951 (33.75) & \\
\hline 2 & $1777(27.37)$ & $1685(29.15)$ & \\
\hline 3 or 4 & $1815(27.95)$ & $1183(20.47)$ & \\
\hline Cohort & & & 0.32 \\
\hline CHARLS & $3933(60.57)$ & $3552(61.45)$ & \\
\hline CHNS & $2560(39.43)$ & $2228(38.55)$ & \\
\hline
\end{tabular}


Table 2

Estimated regression coefficients $(\beta)$ from the generalized additive model with a factor-smooth interaction

\begin{tabular}{|c|c|c|c|c|c|c|c|}
\hline & & \multicolumn{2}{|c|}{ CHARLS data } & \multicolumn{2}{|c|}{ CHNS data } & \multicolumn{2}{|c|}{ Pooled data } \\
\hline & & $\beta(\mathrm{SE})$ & $\begin{array}{l}P \\
\text { value }\end{array}$ & $\beta(\mathrm{SE})$ & $\begin{array}{l}P \\
\text { value }\end{array}$ & $\beta$ (SE) & $\begin{array}{l}P \\
\text { value }\end{array}$ \\
\hline Intercept & & $\begin{array}{l}100.71 \\
(3.27)\end{array}$ & $\begin{array}{l}<2 \mathrm{e}^{-} \\
16\end{array}$ & $\begin{array}{l}107.32 \\
(4.53)\end{array}$ & $\begin{array}{l}<2 \mathrm{e}^{-} \\
16\end{array}$ & $\begin{array}{l}105.12 \\
(2.7)\end{array}$ & $\begin{array}{l}<2 \mathrm{e}^{-} \\
16\end{array}$ \\
\hline Age & Per 1 year & $0.34(0.05)$ & $\begin{array}{l}1.04 \mathrm{e}- \\
11\end{array}$ & $\begin{array}{l}0.35 \\
(0.07)\end{array}$ & $\begin{array}{l}1.03 e- \\
07\end{array}$ & $\begin{array}{l}0.36 \\
(0.04)\end{array}$ & $\begin{array}{l}<2 \mathrm{e}^{-} \\
16\end{array}$ \\
\hline \multirow[t]{2}{*}{ Sex } & Female & \multicolumn{2}{|l|}{ Reference } & \multicolumn{2}{|l|}{ Reference } & \multicolumn{2}{|l|}{ Reference } \\
\hline & Male & $\begin{array}{l}-6.13 \\
(1.05)\end{array}$ & $\begin{array}{l}5.74 \mathrm{e}- \\
09\end{array}$ & $\begin{array}{l}-7.47 \\
(1.39)\end{array}$ & $\begin{array}{l}7.53 e- \\
08\end{array}$ & $\begin{array}{l}-6.67 \\
(0.84)\end{array}$ & $\begin{array}{l}1.79 e- \\
15\end{array}$ \\
\hline \multirow[t]{2}{*}{$\begin{array}{l}\text { Sex*BMl } \\
\text { (smooth) }\end{array}$} & Female & $\begin{array}{l}\text { See Fig. } 2 \\
(A)\end{array}$ & $\begin{array}{l}3.88 \mathrm{e}- \\
08\end{array}$ & $\begin{array}{l}\text { See Fig. } 2 \\
\text { (B) }\end{array}$ & $\begin{array}{l}2.76 \mathrm{e}- \\
07\end{array}$ & $\begin{array}{l}\text { See Fig. } 2 \\
\text { (C) }\end{array}$ & $\begin{array}{l}2.22 \mathrm{e}- \\
14\end{array}$ \\
\hline & Male & $\begin{array}{l}\text { See Fig. } 2 \\
\text { (A) }\end{array}$ & $\begin{array}{l}3.97 e- \\
14\end{array}$ & $\begin{array}{l}\text { See Fig. } 2 \\
\text { (B) }\end{array}$ & $\begin{array}{l}1.57 \mathrm{e}- \\
13\end{array}$ & $\begin{array}{l}\text { See Fig. } 2 \\
\text { (C) }\end{array}$ & $\begin{array}{l}<2 \mathrm{e}^{-} \\
16\end{array}$ \\
\hline \multirow[t]{2}{*}{ Residence } & Urban & \multicolumn{2}{|l|}{ Reference } & \multicolumn{2}{|l|}{ Reference } & \multicolumn{2}{|l|}{ Reference } \\
\hline & Rural & $\begin{array}{l}\rrbracket-0.27 \\
(0.83)\end{array}$ & 0.750 & $\begin{array}{l}\searrow-4.76 \\
(1.18)\end{array}$ & $\begin{array}{l}5.30 \mathrm{e}- \\
05\end{array}$ & $\begin{array}{l}\nabla-1.88 \\
(0.68)\end{array}$ & 0.006 \\
\hline \multirow[t]{2}{*}{ Education } & $\begin{array}{l}\text { Below high } \\
\text { school }\end{array}$ & \multicolumn{2}{|l|}{ Reference } & \multicolumn{2}{|l|}{ Reference } & \multicolumn{2}{|l|}{ Reference } \\
\hline & $\begin{array}{l}\text { High school or } \\
\text { above }\end{array}$ & $0.33(1.32)$ & 0.805 & $\begin{array}{l}1.27 \\
(1.39)\end{array}$ & 0.358 & $\begin{array}{l}1.26 \\
(0.94)\end{array}$ & 0.180 \\
\hline \multirow[t]{2}{*}{ Marital status } & Others & \multicolumn{2}{|l|}{ Reference } & \multicolumn{2}{|l|}{ Reference } & \multicolumn{2}{|l|}{ Reference } \\
\hline & Married & $\begin{array}{l}\searrow-0.56 \\
(1.32)\end{array}$ & 0.617 & $\begin{array}{l}0.22 \\
(1.65)\end{array}$ & 0.892 & $\begin{array}{l}\searrow-0.36 \\
(0.93)\end{array}$ & 0.702 \\
\hline \multirow[t]{2}{*}{ Smoking } & No & \multicolumn{2}{|l|}{ Reference } & \multicolumn{2}{|l|}{ Reference } & \multicolumn{2}{|l|}{ Reference } \\
\hline & Yes & $\begin{array}{l}\otimes-1.11 \\
(1.06)\end{array}$ & 0.294 & $\begin{array}{l}\searrow-0.48 \\
(1.42)\end{array}$ & 0.734 & $\begin{array}{l}\nabla-0.8 \\
(0.85)\end{array}$ & 0.343 \\
\hline \multirow[t]{2}{*}{ Drinking } & No & \multicolumn{2}{|l|}{ Reference } & \multicolumn{2}{|l|}{ Reference } & \multicolumn{2}{|l|}{ Reference } \\
\hline & Yes & $\begin{array}{l}\bigotimes-1.22 \\
(1.32)\end{array}$ & 0.188 & $\begin{array}{l}\bigotimes-0.78 \\
(1.34)\end{array}$ & 0.562 & $\begin{array}{l}\bigotimes-1.08 \\
(0.77)\end{array}$ & 0.158 \\
\hline \multirow[t]{3}{*}{ Cohort } & CHNS & & & & & Reference & \\
\hline & CHARLS & & & & & $\begin{array}{l}3.90 \\
(0.64)\end{array}$ & $\begin{array}{l}1.41 \mathrm{e}- \\
09\end{array}$ \\
\hline & & \multicolumn{2}{|c|}{ R-sq.(adj) $=0.0299$} & \multicolumn{2}{|c|}{ R-sq.(adj) $=0.0419$} & \multicolumn{2}{|c|}{ R-sq.(adj) $=0.0381$} \\
\hline
\end{tabular}


Table 3

Slopes $(95 \% \mathrm{Cls})$ of the association of BMI with LDL cholesterol among individuals below or above the inflection point

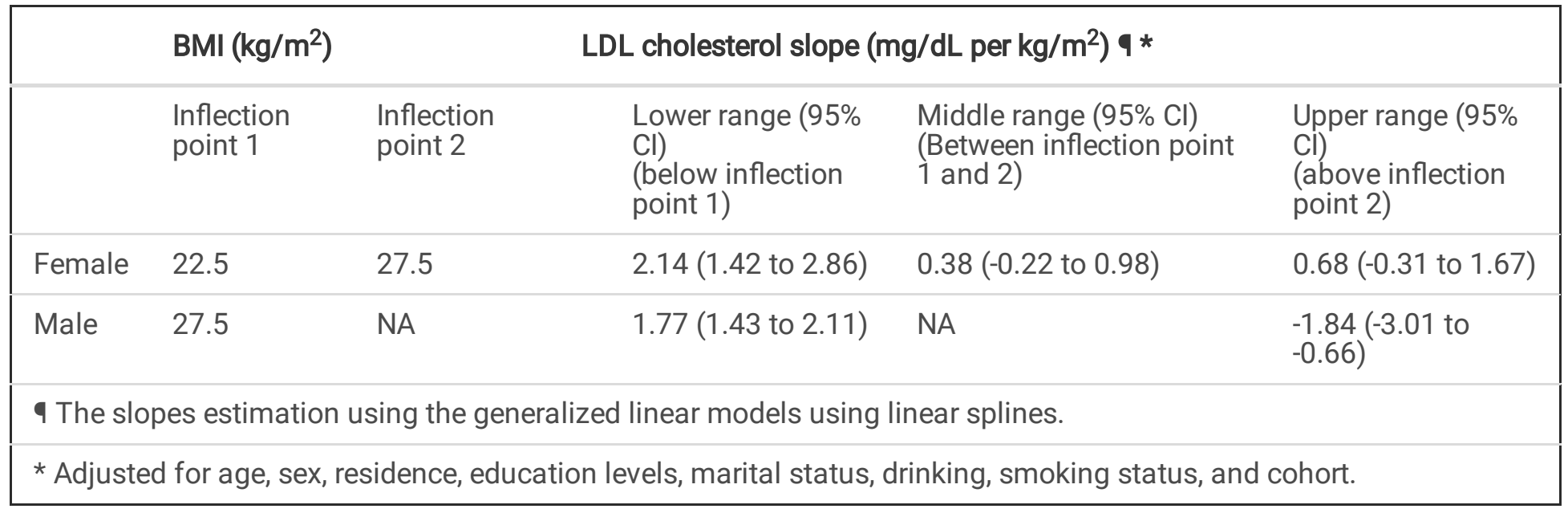

\section{Figures}

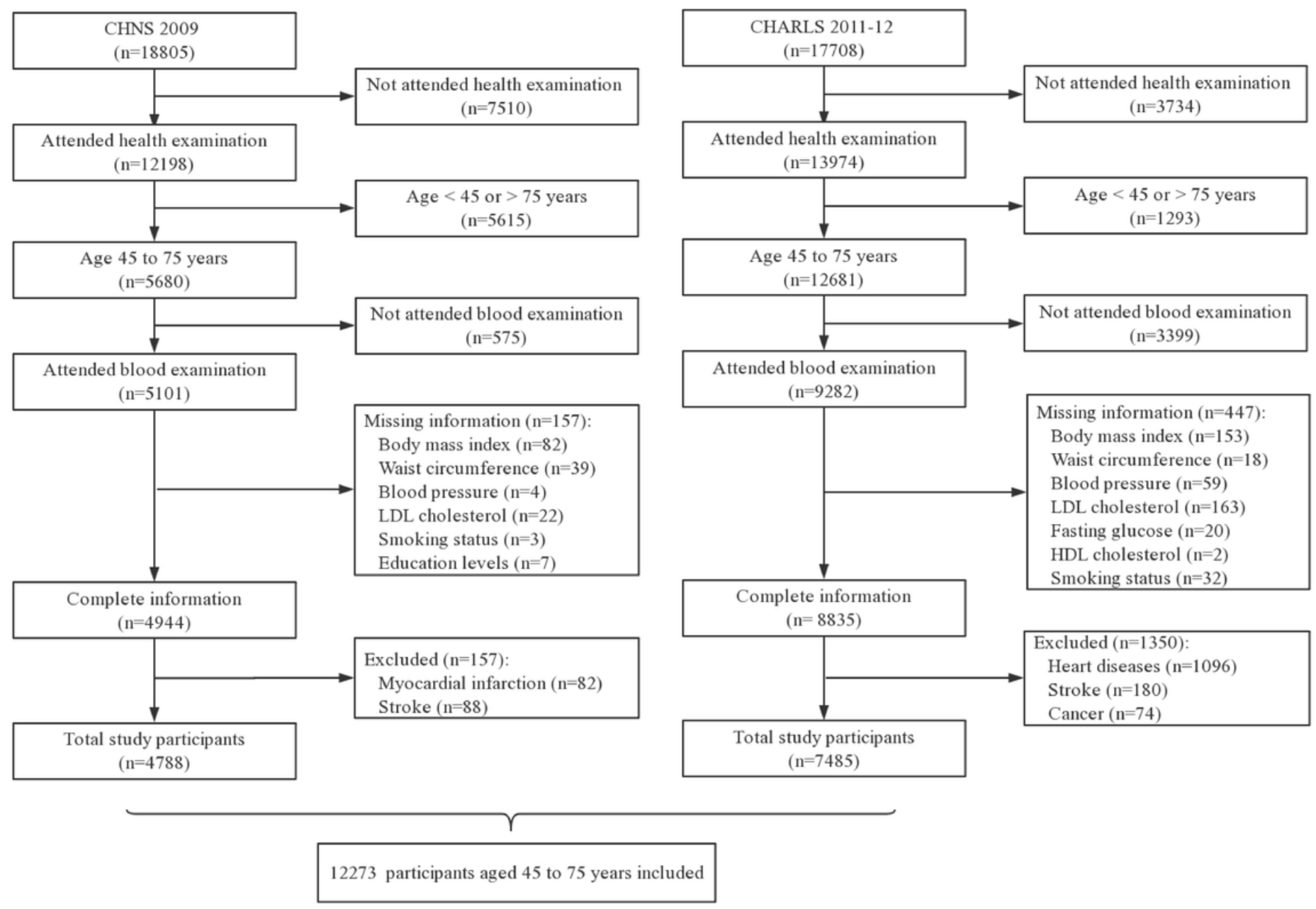

Figure 1 


\section{A CHARLS data}

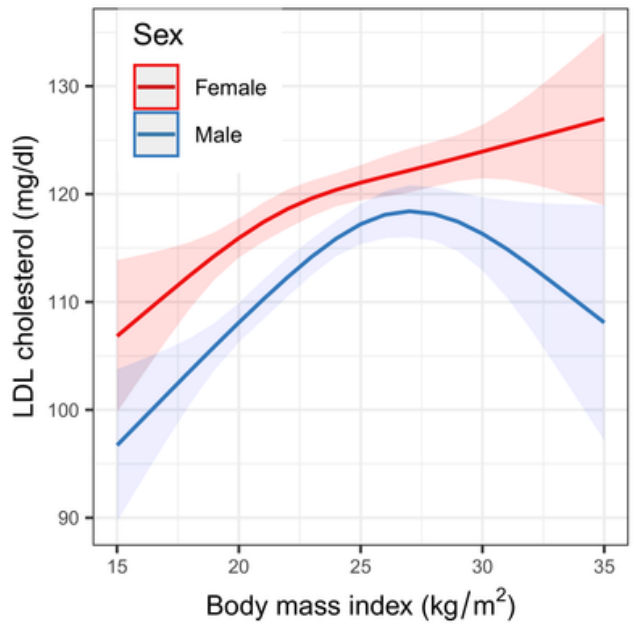

B CHNS data

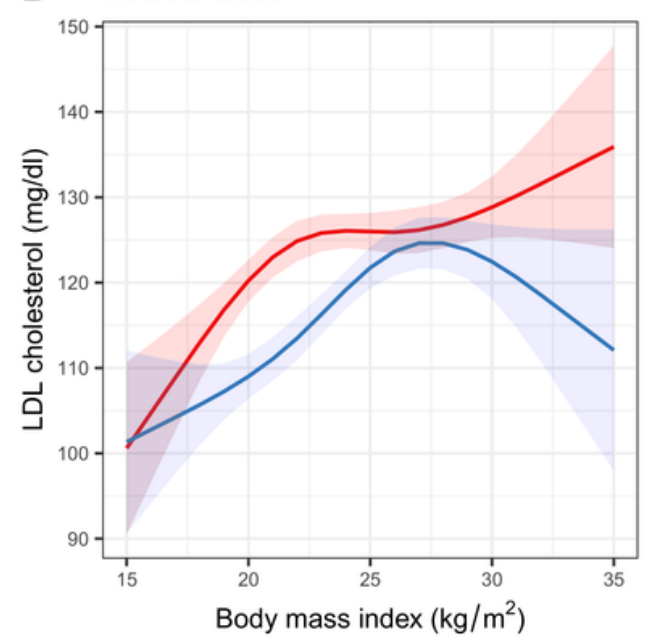

C Pooled data

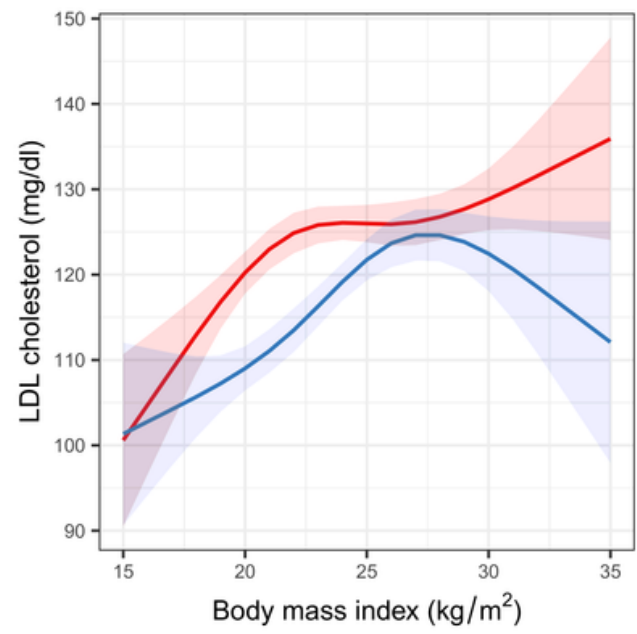

Figure 2

The nonlinear relationship between BMI and LDL-C in female and male using generalized additive models with the factor-smooth interaction terms for sex*BMI.

\section{Supplementary Files}

This is a list of supplementary files associated with this preprint. Click to download.

- Supplementary20210804.docx 